\title{
COMBO-FISH: specific labeling of nondena- tured chromatin targets by computer-selected DNA oligonucleotide probe combinations
}

\author{
Michael Hausmann ${ }^{1,2}$, Ralph Winkler ${ }^{1}$, Georg Hildenbrand ${ }^{1}$, Jutta Finsterle ${ }^{1}$, Andrea Weisel ${ }^{1}$, \\ Alexander Rapp ${ }^{3}$, Eberhard Schmitt ${ }^{3}$, Siegfried Janz ${ }^{4}$, Christoph Cremer $^{1}$
}

BioTechniques 35:564-577 (September 2003)

\begin{abstract}
Here we present the principle of fluorescence in situ hybridization (FISH) with combinatorial oligonucleotide (COMBO) probes as a new approach for the specific labeling of genomic sites. COMBO-FISH takes advantage of homopurine/homopyrimidine oligonucleotides that form triple helices with intact duplex genomic DNA, without the need for prior denaturation of the target sequence that is usually applied for probe binding in standard FISH protocols. An analysis of human genome databases has shown that homopurine/homopyrimidine sequences longer than $14 \mathrm{bp}$ are nearly homogeneously distributed over the genome, and they represent from $1 \%$ to $2 \%$ of the entire genome. Because the observation volume in a confocal laser-scanning microscope equipped with a high numerical aperture lens typically corresponds to an approximate 250-kb chromatin domain in a normal mammalian cell nucleus, this volume should contain 150-200 homopurine/homopyrimidine stretches. Using DNA database information, one can configure a set of distinct, uniformly labeled oligonucleotide probes from these stretches that is expected to exclusively co-localize within a 250-kb chromatin domain. Due to the diffraction-limited resolution of a microscope, the fluorescence signals of the configured oligonucleotide probe set merge into a typical, nearly homogeneous FISH spot. Using a set of 32 homopyrimidine probes, we performed experiments in the Abelson murine leukemia region of human chromosome 9 as some of the very first proofs-of-principle of COMBO-FISH. Although the experimental protocol currently contains several steps that are incompatible with living cell conditions, the theoretical approach may be the first methodological advance toward the long-term but still elusive goal of carrying out specific FISH in high-resolution fluorescence microscopy of vital cells.
\end{abstract}

\section{INTRODUCTION}

Fluorescence in situ hybridization (FISH) has become a powerful tool to specifically label DNA sequences in interphase cell nuclei and on metaphase chromosomes. FISH protocols are routinely applied to a variety of technical modifications in basic and medical research and clinical diagnostics $(1,2)$. The commonly accepted molecular mechanism of nonenzymatic FISH to eukaryotic DNA targets is the generation of a new DNA double-stranded hybrid by the specific binding of a single-stranded DNA probe to the complementary single-stranded DNA target sequence. However, this mechanism requires DNA denaturation [i.e., the separation of the Watson-Crick bonds of the double-stranded DNA (dsDNA) probe and the dsDNA target]. In nearly all FISH protocols, denaturation of the probe and target DNA is performed by heat treatment from $70^{\circ}$ to $95^{\circ} \mathrm{C}$ in a buffer containing chaotropic agents such as formamide (3-5).

This denaturation procedure is an insurmountable limit to transfer FISH into protocols for the analysis of dynamic processes of specific chromatin domains in vivo $(6,7)$. Although alternative in vivo labeling techniques using green fluorescent proteins have recently made considerable progress $(8-10)$, they require prior genetic alterations in the cells to be studied. Such methods may be highly valuable for research purposes but are unlikely to be used for routine applications or medical diagnostics. Therefore, a generally applicable labeling technique that omits the denaturation of the chromatin target appears to be highly desirable. This seems to be useful in the cytogenetic research of vital cells and in the clinical diagnosis of fixed specimen whenever gentle treatment is required.

Some years ago, a FISH procedure called fast-FISH was introduced (11-14), in which chaotropic agents such as formamide or other equivalent denaturing chemical agents were omitted in the hybridization buffer. Based on fast-FISH, early experiments were presented in which metaphase chromosomes were hybridized at $37^{\circ} \mathrm{C}$

\footnotetext{
${ }^{1}$ Kirchhoff-Institute of Physics, University of Heidelberg, Heidelberg, ${ }^{2}$ Institute of Pathology, University Hospital, Freiburg,

${ }^{3}$ Institute of Molecular Biotechnology, Jena, Germany, and ${ }^{4}$ National Institutes of Health, Bethesda, MD, USA
} 
without formamide treatment or thermal denaturation of the DNA target (low temperature FISH) (15). These results were verified for the region q12 of human chromosome 1 using the DNA probe pUC $1.77(16,17)$. Images of metaphase chromosomes obtained by near-field scanning optical microscopy after the application of low temperature FISH revealed a better chromosomal morphology in the sub-hundred nanometer resolution regime, compared to metaphase chromosomes subjected to a standard FISH procedure with formamide exposure and thermal target denaturation $(17,18)$. In these reports on low temperature FISH, triple-stranded DNA binding was suggested as a possible hybridization mechanism, which was a hypothesis supported by the results of other groups $(19,20)$.

Triple helix formation is possible for oligonucleotides that can bind to a homopurine/hompyrimidine DNA duplex in the major groove by the formation of Hoogsteen base pairs with the homopurine strand (21-23). Triplex formation is highly specific (24) so that Hoogsteen base pairing can be used for the sequence-specific recognition of dsDNA sequences (25-27). It has had numerous applications in biotechnology, such as gene targeting, mutagenesis, and inhibition of gene activity (28-31). Conditions suitable for third-strand in situ hybridization (TISH) have been found for metaphase spreads and interphase cell nuclei after methanol/acetic acid fixation, dehydration, and air-drying (20). In contrast to the earlier low temperature FISH experiments, TISH only used one 16-nucleotide homopyrimidine DNA probe to a unique multicopy $\alpha$-satellite target sequence on chromosome 17 and was performed at an increased hybridization temperature $\left(45^{\circ} \mathrm{C}\right)$ for probe and chromosomal targets accompanied by post-hybridization washing at $51^{\circ} \mathrm{C}$.

Currently, all these low temperature FISH protocols have been restricted to only a few select DNA sequences $(16,17,20,32)$. Here we describe the principle of combinatorial oligonucleotide-FISH (COMBO-FISH) (33), which should allow for the specific labeling of any given target region by the triple-stranded binding of a specific combination of oligonucleotide probes. We report the first experimental evidence that indicates the feasibility of such a labeling approach, using the Abelson murine leukemia (ABL) region on $9 \mathrm{q} 34$ as an example.

\section{MATERIALS AND METHODS}

\section{Computer Program for DNA Database Evaluation}

To screen homopurine/homopyrimidine sequences in the human genome, the European Molecular Biology Laboratory (EMBL) and DKFZ nucleotide sequence databases were accessed using the Heidelberg Unix Sequence Analysis Resources (HUSAR), kindly provided by the Biocomputing Service Group of the German Cancer Research Center (DKFZ; Heidelberg, Germany).

A menu-controlled sequence analysis program called Homo-P/Y was written under the Linux ${ }^{\circledR}$ operating system. Homo-P/Y supports the HUSAR software package and can read a sequence file in ASCII-format, from which a new file can be produced containing all the homopurine/homopyrimidine sequences, respectively, which are longer than a given minimum base number. Homopurine/homopyrimidine sequences of a given rate of adenine/ guanine or cytosine/thymine can also be identified.

To find all copies of these sequences in the genome, the HUSAR program blastn [standard nucleotide-nucleotide BLAST (Basic Local Alignment Search Tool)] is used to determine all matches and mismatches to repetitive sequences. Using the FASTA program, one can find other matches to genome sequences, and the homopurine/homopyrimidine sequences can be eliminated from the list of labeling sequences appropriate for COMBO-FISH. Finally, a set of sequences remain that exist only in one copy or a very few copies of the genome. This set is then expressed either in homopurine or in corresponding homopyrimidine sequences, whereas the orientation of the oligomers has to follow the Hoogsteen triple-stranded binding conditions (27).

To accelerate the search of appropriate oligonucleotide combinations and to 
screen the different genome databases, additional programs were developed and applied to the human and mouse databases (E. Schmitt and M. Hausmann, manuscript in preparation).

\section{Specimen Preparation}

For fast-FISH experiments, human fibroblast cells (MCR5) were grown under standard conditions, washed three times in phosphate-buffered saline (PBS), and harvested using a trypsine/EDTA treatment ( $2 \mathrm{~mL}$ EDTA for $3 \mathrm{~min}$ and $3 \mathrm{~mL}$ trypsine until the cells detach). Hypotonic treatment was performed with $0.2 \mathrm{M} \mathrm{KCl}$ at $37^{\circ} \mathrm{C}$ for $20 \mathrm{~min}$. The cells were fixed in ice-cold methanol/acetic acid (3:1) and stored at $-20^{\circ} \mathrm{C}$ for $24 \mathrm{~h}$. The cell nuclei were isolated by dropping the suspension on precleaned slides.

For low temperature FISH and COMBO-FISH experiments, human peripheral blood lymphocytes were prepared under standard conditions. After hypotonic treatment with $0.075 \mathrm{KCl}$ at $37^{\circ} \mathrm{C}$ from 10 to $25 \mathrm{~min}$, the cells were fixed in $4^{\circ} \mathrm{C}$ cold methanol/acetic acid (3:1) and dropped on precleaned slides. The specimen was stored in pure ethanol at $4^{\circ} \mathrm{C}$ for at least 2 days.

\section{Control Experiments}

We performed two types of control experiments with oligonucleotide probes: fast-FISH (with thermal DNA target denaturation but without the use of chaotropic agents) and low temperature FISH (without thermal DNA target denaturation or the use of chaotropic agents). For these experiments, homopyrimidine probes were selected that can only bind by Watson-Crick pairing in the $\mathrm{ABL}$ region due to their orientation.

Fast-fluorescence in situ hybridization. For the ABL region on chromosome 9, homopurine and homopyrimidine oligonucleotide probes with parallel orientation to the chromosomal sequences were commercially synthesized (MWG-Biotech GmbH, Ebensberg, Germany). Twelve of these probes were labeled with fluorescein isothiocyanate (FITC) at the $3^{\prime}$ end and $5^{\prime}$ end, and eight were biotinylated at the $5^{\prime}$ end for detection with a Cy ${ }^{\mathrm{TM}} 5$ - streptavidin conjugate.

Fast-FISH was performed as previously described (12), with slight modifications. Briefly, $12 \times 0.5 \mu \mathrm{L}$ FITC-labeled oligonucleotide probes and $8 \times 1 \mu \mathrm{L}$ biotinylated oligonucleotide probes were diluted in $1.2 \mu \mathrm{L} 20 \times$ standard saline citrate (SSC) and 1.2 $\mu \mathrm{L}$ AP buffer (100 mM Tris, $\mathrm{pH} 8.3$, $20 \mathrm{mM} \mathrm{MgCl}_{2}, 500 \mathrm{mM} \mathrm{KCl}$ ), dropped on the specimen slides, covered with a coverslip, and sealed with Fixogum rubber cement (Mercateo, München, Germany). Target denaturation was performed at $95^{\circ} \mathrm{C}$ for $5 \mathrm{~min}$, followed by hybridization at $70^{\circ} \mathrm{C}$ for $2 \mathrm{~h}$. After washing in $2 \times \mathrm{SSC}$ at $37^{\circ} \mathrm{C}$ for $10 \mathrm{~min}$, $20 \mu \mathrm{L}$ Cy5-streptavidin conjugate diluted in water (1:400) were added and incubated at room temperature for 45 min. The specimen was then washed in $4 \times$ SSC plus $0.1 \%$ Igepal $^{\circledR}$ three times for $3 \mathrm{~min}$, air-dried, and mounted in VECTASHIELD ${ }^{\circledR}$ antifade solution (Vector Laboratories, Burlingame, CA, USA).

Low temperature fluorescence in situ hybridization. For the ABL region on chromosome 9, 32 homopyrimidine oligonucleotide probes with a FITC molecule at both ends were commercially synthesized. The probes displayed an orientation that was antiparallel to the purine target strand and parallel to the complementary pyrimidine target strand.

The hybridization mixture consisted of $137 \mathrm{ng}$ probe DNA in equal amounts of all homopyrimidine oligonucleotides, $0.5 \mathrm{M}$ sodium acetate (pH 5.0, 5.5, 6.0, and 6.5), $3 \mathrm{M} \mathrm{NaCl}$, $0.6 \mathrm{M} \mathrm{MgCl}_{2}$, and $10 \mu \mathrm{L}$ water, which resulted in a final volume of $30 \mu \mathrm{L}$. This mixture was pipetted onto the specimen slides, covered with a coverslip, and sealed with Fixogum rubber cement. In situ hybridization was performed at $37^{\circ} \mathrm{C}$ for $25,50,100$, and $200 \mathrm{~h}$. The coverslips were then carefully removed, and the specimens were washed in $4 \times \mathrm{SSC}, \mathrm{pH} 7.0$, with $0.2 \%$ Tween ${ }^{\circledR} 20$ (Fluka, Buchs, Switzerland) for $5 \mathrm{~min}$. The slides were then exposed to $50 \%$ and $100 \%$ ethanol for 5 min each and mounted in $15 \mu \mathrm{L}$ VECTASHIELD antifade solution containing $0.05 \mathrm{mM}$ propidium iodide. For microscopy, the slides were again covered with a coverslip.
Fluorescence In Situ Hybridization Using Combinatorial Oligonucleotide Probes

For the $\mathrm{ABL}$ region on chromosome 9, 32 homopyrimidine oligonucleotide probes with an Alexa ${ }^{\mathrm{TM}} 514$ molecule at both ends were commercially synthesized. The probes displayed an orientation that was parallel to the purine target strand and anti-parallel to the complementary pyrimidine target strand, which indicates that the probes can only bind to the DNA at the ABL region via Hoogsteen bondings.

Before in situ hybridization, the air-dried specimen was subjected to an additional pretreatment as previously described (17). The specimen was incubated in $200 \mu \mathrm{L}$ RNase A $(10 \mathrm{mg} / \mathrm{mL}$ in water with $10 \mathrm{mM}$ Tris- $\mathrm{HCl}, \mathrm{pH} 8.0$, diluted to $100 \mu \mathrm{g} / \mathrm{mL}$ at $37^{\circ} \mathrm{C}$ for $1 \mathrm{~h}$. After washing twice in $2 \times \mathrm{SSC}$ for $5 \mathrm{~min}$ each, the slides were incubated in 500 $\mu \mathrm{L} 10 \mathrm{mM} \mathrm{HCl}$ at $37^{\circ} \mathrm{C}$ for $5 \mathrm{~min}$, followed by a treatment with pepsin $(50 \mu \mathrm{L}$ stock solution; consisting of $50 \mu \mathrm{g} / \mathrm{mL}$ in $10 \mathrm{mM} \mathrm{HCl}$ diluted with $50 \mu \mathrm{L} 10$ $\mathrm{mM} \mathrm{HCl}$ ) at $37^{\circ} \mathrm{C}$ for $15 \mathrm{~min}$. The reaction was stopped by using pure water for 1 min. After washing in $2 \times$ SSC twice for 5 min each, an additional fixation in $4 \%$ formaldehyde was performed for 10 $\min$. The slides were then washed in $2 x$ SSC twice for $5 \mathrm{~min}$ each, dehydrated by an ethanol series $(70 \%, 90 \%$, and $96 \%$ ) for 2 min each, and air-dried.

The hybridization mixture consisted of a total of $274 \mathrm{ng}$ probe DNA (8 $\mu \mathrm{L})$ in equal amounts of all homopyrimidine oligonucleotides, $3 \mathrm{M}$ sodium acetate $(6 \mu \mathrm{L} ; \mathrm{pH} 5.0), 3 \mathrm{M} \mathrm{NaCl}(5$ $\mu \mathrm{L} ; \mathrm{pH} 5.0), 3 \mathrm{M} \mathrm{MgCl}_{2}(5 \mu \mathrm{L} ; \mathrm{pH}$ 5.0), $205 \mathrm{mM}$ naphtylquinoline (4.5 $\mu \mathrm{L}$ ), and $30 \mu \mathrm{L}$ water. This mixture was pipetted onto the specimen slides, covered with a coverslip, and incubated in a humidified chamber at $37^{\circ} \mathrm{C}$ for 24 h. The coverslips were subsequently carefully removed, and the specimens were washed in $4 \times \mathrm{SSC}, \mathrm{pH} 7.0$, with $0.2 \%$ Tween 20 for $5 \mathrm{~min}$. The slides were then exposed to $50 \%$ and $100 \%$ ethanol for 5 min each and mounted in $15 \mu \mathrm{L}$ VECTASHIELD antifade solution containing $50 \mu \mathrm{M} 4^{\prime}, 6^{\prime}$-diamidino2-phenylindole hydrochloride (DAPI). For microscopy, the slides were again covered with a coverslip. 


\section{Microscopy}

For the control experiments, we used a confocal laser-scanning microscope (Leica TCS NT; Leica Microsystems, Bensheim, Germany) that was equipped with a Plan $\mathrm{Apo}^{\mathrm{TM}} 63 \times$ numerical aperture (N.A.) 1.4 oil immersion objective and an argon-krypton laser for excitation at 488 (FITC) and $647 \mathrm{~nm}$ (Cy5) (Leica Microsystems). For the COMBO-FISH experiments, we used another confocal laser-scanning microscope (Leica TCS MP) that was equipped with a Plan Apo 100 N.A. 1.4 oil immersion objective and an argon-kryton laser for excitation at $488 \mathrm{~nm}$. (Alexa 514 dye can also be excited with the 488-nm laser line. This dye was chosen due to its good photostability.) The appropriate excitation wavelength was selected by an acousto-optical tuneable filter (part of the instrument). The fluorescence was detected on photomultiplier tubes via the appropriate filter settings. Typi- cally, 20-40 optical sections were acquired per cell nucleus, corresponding to a step width of about $200 \mathrm{~nm}$ in the axial direction. To increase the number of photons registered and thus the localization precision of the fluorescent sites (34), an 8 times averaging was applied. An image frame of $512 \times 512$ pixels was acquired in approximately $1.6 \mathrm{~s}$, which resulted in an average laser focus exposure time of $6.2 \mu \mathrm{s}$. For image visualization, we used the Khoros software package (Khoral, Albuquerque, NM, USA) (35). The images were exposed to a $3 \times 3 \times 3$ median filter, and the average background intensity was subtracted.

\section{RESULTS}

\section{Principle of Fluorescence In Situ Hybridization Using Combinatorial Oligonucleotide Probes}

The principle of COMBO-FISH

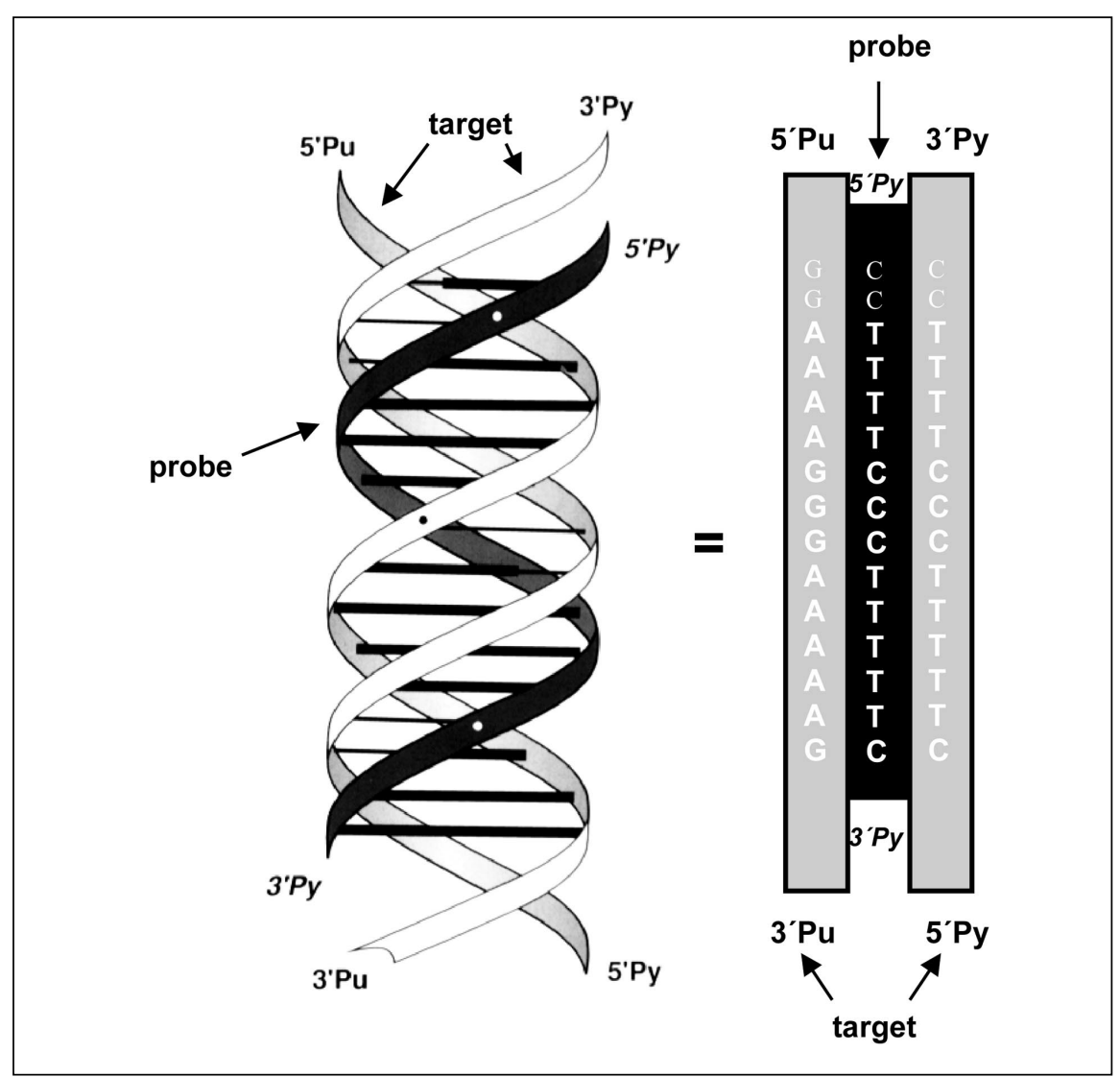

Figure 1. Representation of the triple-stranded binding of a homopyrimidine probe. [For an example of a sequence in the Abelson murine leukemia (ABL) region, see Table 3.] 
(33) is based on the physicochemical prerequisites of DNA triple helices and constraints of microscopic imaging. Homopurine/homopyrimidine oligonucleotide third strands bind sequenceand polarity-specific within the major groove to a purine-rich strand of DNA duplex target sequences $(21-23,25)$ in the chromosomes and chromatin of mammalian cell nuclei $(36,37)$. A third homopurine strand can bind anti-parallel by reverse Hoogsteen hydrogen bonding (i.e., from the $5^{\prime}$ end to the $3^{\prime}$ end) or a third homopyrimidine strand can bind parallel by Hoogsteen hydrogen bonding (i.e., from the $3^{\prime}$ end to the $5^{\prime}$ end (Figure 1) $(24,27,38)$.

In contrast to the Watson-Crick bonding of dsDNA, the length of the third strand has a strong influence on the bonding enthalpy $\Delta \mathrm{H}$ of triple strands. With the number of nucleotides, $\Delta \mathrm{H}$ increases to a maximum value of 12 nucleotides. For longer oligonucleotide sequences, it decreases (39-41). Thus, it appears to be feasible that homopurine/homopyrimidine oligonucleotide probes should have a length of 10-35 bases (42).

Because it is necessary to protonate cytosine, homopyrimidine oligonucleotides other than poly(T) form a distinctive complex with a purine-pyrimidine double strand only at a low $\mathrm{pH}(\leq 6.0)$ (43). Triplex formation with homopurine oligonucleotides does not depend on $\mathrm{pH}$ (44).

The image point of the smallest spatially resolvable object in a light microscope is described by the point spread function (PSF) volume (45). For conventional fluorescence microscopy, the PSF is given by an ellipsoid spanning the full width at half maximum (FWHM) of the PSF. For an objective lens of high numerical aperture in a confocal laser-scanning microscope and standard specimen conditions of cell nuclei, the PSF volume is approximately $0.02 \mu \mathrm{m}^{3}$. With a homogeneous chromatin density and a diploid DNA set $\left(6 \times 10^{9} \mathrm{bp}\right)$ in a human cell nucleus of about $10 \mu \mathrm{m}$ diameter and a volume of about $500 \mu \mathrm{m}^{3}$, the PSF volume would contain $\left(6 \times 10^{9} \mathrm{bp} / 500 \mu \mathrm{m}^{3}\right) \times$ $0.02 \mu \mathrm{m}^{3}$, which is approximately 250 $\mathrm{kb}$ DNA.

For COMBO-FISH, a genome locus of the size of a PSF volume or larger is

Table 1. Purine/Pyrimidine Statistics of the Entries Analyzed

\begin{tabular}{|lcccc|}
\hline & Genes & Centromeres & Telomeres & $\begin{array}{c}\text { Repetitive } \\
\text { Sequences }\end{array}$ \\
\hline Entries analyzed $(n)$ & 472 & 71 & 709 & 703 \\
Bases $(n)$ & $24,393,104$ & 215,637 & 607,460 & 491,595 \\
Purines $(n)$ & $12,165,597$ & 110,892 & 304,819 & 248,241 \\
Pyrimidines $(n)$ & $12,227,507$ & 104,745 & 302,641 & 243,354 \\
Rate of purines & 0.4987 & 0.5143 & 0.5018 & 0.5050 \\
Rate of pyrimidines & 0.5013 & 0.4867 & 0.4982 & 0.4950 \\
Longest homosequence & 499 & 73 & 227 & 190 \\
\hline
\end{tabular}

Table 2. Computer Analysis of Three Coherent Regions of the EMBL Database

\begin{tabular}{|c|c|c|c|c|}
\hline & T-Cell 1 & T-Cell 2 & Contig & Total \\
\hline Entries & 5 & 3 & 3 & 11 \\
\hline Bases & $1,071,917$ & 715,247 & 959,073 & $2,746,237$ \\
\hline Homosequences ( $\geq 15$ bases) & 825 & 479 & 705 & 2009 \\
\hline $\begin{array}{l}\text { Mean of homosequences } \\
\text { ( } \geq 15 \text { bases) per } 50 \mathrm{~kb} \text { segment }\end{array}$ & 38.5 & 33.5 & 36.8 & 36.2 \\
\hline$+/-S D$ & 8.1 & 9.3 & 7.6 & 8.4 \\
\hline $\begin{array}{l}\text { Mean of homosequences } \\
\text { ( } \geq 15 \text { bases) per } 250 \mathrm{~kb} \text { segment } \\
\text { (PSF volume) }\end{array}$ & 192.4 & 167.4 & 183.8 & 181.2 \\
\hline $\begin{array}{l}\text { Absolute no. of bases in } \\
\text { homosequences }\end{array}$ & 17,117 & 9310 & 14,908 & 41,335 \\
\hline $\begin{array}{l}\text { Relative no. of bases in } \\
\text { homosequences }\end{array}$ & $1.60 \%$ & $1.30 \%$ & $1.55 \%$ & $1.51 \%$ \\
\hline $\begin{array}{l}\text { Mean length of homosequences } \\
\text { ( } \geq 15 \text { bases })\end{array}$ & 20.8 & 19.4 & 21.1 & 20.8 \\
\hline
\end{tabular}

screened in a DNA sequence database for all homopurine/homopyrimidine segments. If the human genome contains about $1 \%$ of its base pairs as homopurine/homopyrimidine segments of a length of 15-35 nucleotides each, and these segments are nearly homogeneously dispersed over coding and noncoding regions, then 150-200 of these segments would be found within a PSF volume. Then, those oligomers that only exist in very few copies in the whole genome and only co-localize at the given genome locus can be determined. This means that even if the individual sequence were not strictly unique, then the COMBO-FISH approach would work as long as the co-localization of the probe set is unique in the haploid genome. As stated earlier, co-local- ization indicates that the positions of all the probes selected are to be found within one PSF volume. Furthermore, if more than one locus exists in the haploid genome for a given sequence, then the spatial distance between them should be larger than the FWHM of the microscope system used. Due to the high amount of nuclear structure revealed in human somatic cell nuclei (6), this condition is very likely to be fulfilled if the respective sequence is complementary to only a few genomic sites. If $10-20$ appropriate sequences were found, then this would result in a fluorescence signal of 20-40 fluorochromes (i.e., fluorochrome molecule position at the $3^{\prime}$ end and the $5^{\prime}$ end of the oligomer). With this label, the genome locus would be identified in a microscope by a merged diffraction 
Table 3. COMBO-FISH Labeling Sites of the ABL Region

\begin{tabular}{|c|c|c|c|}
\hline Block & Homopurine Sequences & Block & Homopyrimidine Sequences \\
\hline \multirow[t]{2}{*}{ I } & 5'-GAGGGGGAGAGAAGGGG-3' & I & 5'-ССТТТTСССТTТTТС--3' \\
\hline & 5'-GGGAGAAGAGGAGGAGA-3' & & 5'-ТССТСТТССССТТТТС-3' \\
\hline III & 5'-AGAAAGAGGAGAGGGAG-3' & III & 5'-СТTTTTССССТTТТTТТ-3' \\
\hline III & 5'-AGGAAGAAAGAGGGAAG-3' & III & 5'-ТСТТТТТСТСССССТТ-3' \\
\hline \multirow[t]{3}{*}{ I } & 5'-GGAGAGGGGAGGAAAAGA-3' & I & 5'-ТTТСССТTССССТСТСТ-3' \\
\hline & 5'-AAAGAGGAGGAAAAAAAA-3' & & 5'-ТССТСССТССТТТССТС-3' \\
\hline & 5'-AAGGAGAGAGAAAAGAAG-3' & & 5'-ТСССтTСттTтСтССтC-3' \\
\hline III & 5'-AGGGGAAAAAAGGGAAGA-3' & & 5'-ТСТTТTСТСтСТСССТт-3' \\
\hline \multirow[t]{2}{*}{ III } & 5'-AGGAGGGGAAGGAAGAAAGAAG-3' & III & 5'-СтTСССССТСТСССТTС-3' \\
\hline & 5'-GGGGGAGGGAGGGAAGGAGGAAG-3' & III & 5'-СТTTTTСТTСССТTTTC-3' \\
\hline \multirow[t]{2}{*}{1} & 5'-GAAAGAAAAAAAGGAAAAGAAAAGG-3' & I & 5'-ТTТССТTТСТСТТССТTТ-3' \\
\hline & 5'-GAGGAAGGAAAGAAAGGAAAGAAAA-3' & & 5'-ТССТТТСТСТСТтСТССС-3' \\
\hline I & 5'-AGAGAAGGGAGGGAAAGAGGAAGAGGAG-3' & III & 5'-ТСТСТTTTСТСТTСТСТT-3' \\
\hline \multirow[t]{5}{*}{1} & 5'-AAAAAAGAAAGAAAAGAAAAGAAAAAGAAAAA-3' & III & 5'-СТССТTСТССТтССТСтСС-3' \\
\hline & & & 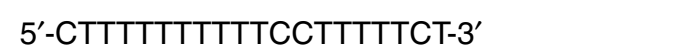 \\
\hline & & & 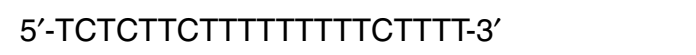 \\
\hline & & III & 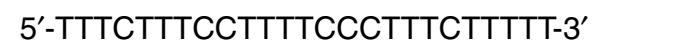 \\
\hline & & III & 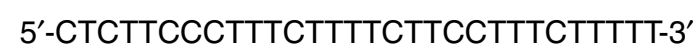 \\
\hline
\end{tabular}

image, or spot, of increased fluorescence intensity of the co-localizing oligonucleotide probes and thus discriminated from the background of the individually dispersed copies of the oligonucleotide probes. Under appropriate conditions (e.g., high photostability and sensitive detection), a single fluorochrome molecule may contribute several thousand detected photons (46). Thus, under such conditions, 20-40 fluorochromes in the detection volume of the PSF (i.e., in the merged diffraction image) may end up

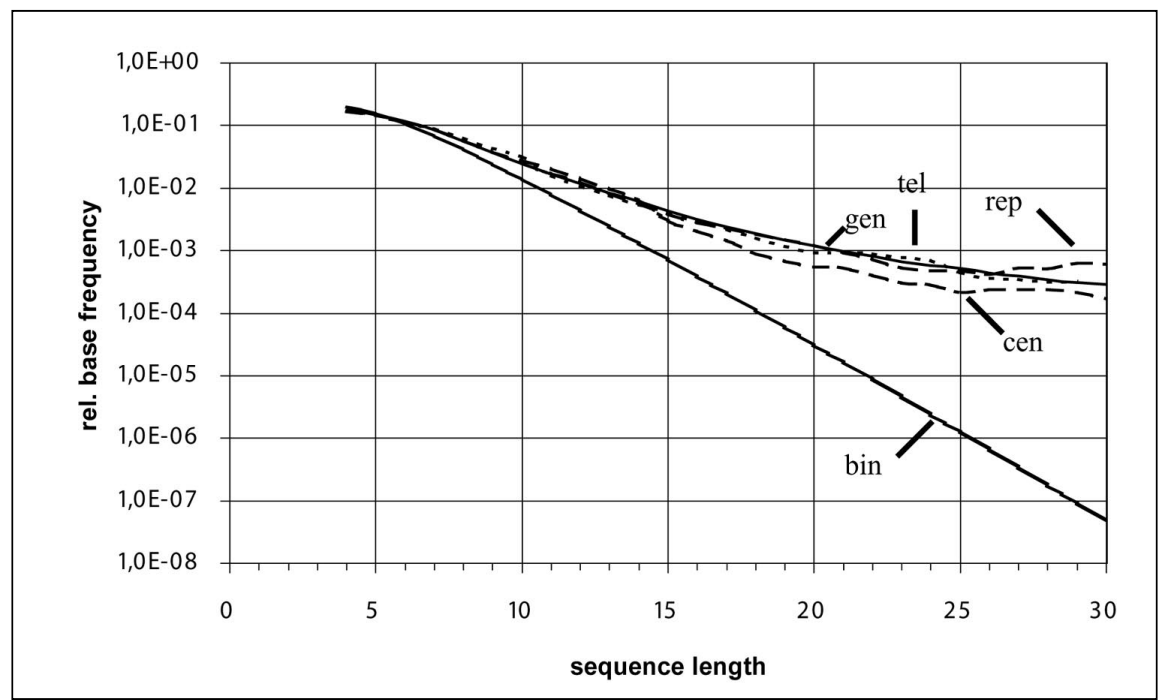

Figure 2. Relative frequency of DNA bases versus sequence length for homopurine/homopyrimidine segments. Rel. base frequency, relative base frequency; bin, expected probability according to binomial statistics; gen, gene coding sequences; cen, centromeres; tel, telomeres; and rep, repetitive sequences. in a total number of detected photons on the order of $10^{5}$. Such high values would clearly be sufficient for microscopic detection.

\section{Distribution of Homopurine/ Homopyrimidine Sequences in the Genome}

The frequency and lengths of the homopurine/homopyrimidine sequences in the human genome that are appropriate for triple helical binding were analyzed for (i) gene coding sequences, (ii) centromeres, (iii) telomeres, and (iv) repetitive sequences. For gene coding sequences, the number of analyzed entries was limited to 472 representative ones with a length of $\geq 20 \mathrm{~kb}$ each. For centromeres, 71 entries were analyzed, and for teleomeres, 709 entries were analyzed. In the case of the repetitive sequences, 703 entries of repetitive and satellite sequences were considered. Table 1 summarizes these results.

The relative frequency of the homopurine/homopyrimidine segments was compared to a binomial distribution, assuming that purine and pyrimidines occur independently from each other 
with the same probability of 0.5 . Figure 2 shows the relative frequency of bases versus the length of the homopurine/ homopyrimidine sequences. For short lengths ( $\leq 10$ bases) the exponential decrease follows the expected binomial distribution. However, for longer sequences, significant differences from the binomial distribution were found (i.e., those homopurine/homopyrimidine sequences highly appropriate for triple-stranded formation were considerably more frequent than expected). Moreover, homopurine/ homopyrimidine sequences longer than 100 bases were found several times. The longest segment of 499 bases was found twice, compared to the expected probability of about $10^{-141}$, according to the binomial distribution. The distributions for all four types of sequences $(i-i v)$ did not differ significantly. From $1 \%$ to $2 \%$ of the genome entries analyzed consisted of homopurine/homopyrimidine sequences between 15 and 35 bases that were appropriate candidates for COMBO-FISH oligonucleotide labeling.

\section{Homogeneity of Homopurine/ Homopyrimidine Distributions}

To test the homogeneity of the homopurine/homopyrimidine distributions, three genome regions covering approximately $3 \mathrm{Mb}(0.1 \%)$ of the human genome were analyzed. In the following, we refer to these genome regions as t-cell 1 (human T cell $\alpha$-locus and $\delta$-locus), t-cell 2 (human T cell $\beta$-locus, 7q35), and contig (sequence between AML1 and CBR1, 21q22).

In the t-cell 1, t-cell 2 , and contig, the amounts of homopurine/homopyrimidine sequences that were 15 bases or more were determined for each 50-kb segment and averaged over 5 segments (i.e., over $250 \mathrm{~kb}$ in spatial extension that corresponds to the practical PSF volume) (Table 2). On average, approximately 180 sequences with a mean length of 20 bases were potential COMBO-FISH labeling sites within each practical PSF volume. Because there were no apparent reasons why homopurine/ homopyrimidine sequences were only restricted to this randomly chosen part of the genome analyzed, we concluded that homopurine/homopyrimidine COMBOFISH labeling sites of $15-35$ bases are likely to be homogeneously dispersed all over the genome.

\section{Probe Design}

We determined the potential COMBO-FISH labeling sites for three different human genome regions, the PraderWilli/Angelman region (15q13), the BCR region (22q11), and the ABL region (9q34). Appropriate homopurine/ homopyrimidine sequences with a low copy number in the whole genome were determined to be co-localized at the given regions only (E. Schmitt and $\mathrm{M}$. Hausmann; manuscript in preparation).

The details for ABL labeling on chromosome $9 \mathrm{q} 34$ are as follows. We found 192 homopurine/homopyrimidine sequences between 15 and 135 nucleotides, which corresponded to approximately $2.4 \%$ of the entire genome region. After the exclusion of highly repetitive sequences, 82 sequences $(0.9 \%)$ between 15 and 89 bases remained for further analysis. High copy number sequences (up to 1000) in the genome were also excluded; finally, 32 sequences remained as potential COMBO-FISH labeling sites for the region chosen. There were 14 homopurines and 18 homopyrimidines, and their lengths varied from 15 to 32 bases (Table 3 ).

\section{Fluorescence In Situ Hybridization Experiments}

Three types of FISH were performed. (i) Fast-FISH of oligonucleotide probes with thermal DNA target denaturation but without the use of chaotropic agents. These control experiments show the size and intensity of typical labeling sites consisting of a set of oligonucleotide probes. (ii) Low temperature FISH of oligonucleotide probes without thermal DNA target denaturation or the use of chaotropic agents. These control experiments show that oligonucleotide probes bind specifically under low temperature conditions. For these experiments, homopyrimidine probes were selected that can only bind by Watson-Crick pairing at the $\mathrm{ABL}$ region due to their orientation. (iii) COMBO-FISH of oligonucleotide probes without thermal DNA target denaturation. These experiments show specific labeling by oligonucleotide probes as a third DNA strand. For these experiments, homopyrimidine probes were selected that can 
only bind by Hoogsteen pairing at the $A B L$ region due to their orientation.

To obtain visual information about the typical labeling pattern, two-color fast-FISH (comprising thermal denaturation of the target) was performed with homopyrimidine oligonucleotide probes of parallel orientation to the purine target. The ABL region (about $230 \mathrm{~kb}$ ) was divided into three subregions, block I (16 kb), block II (150 kb), and block III (67 kb). Block I was labeled with eight oligonucleotide probes of a total length of 170 bases. Each probe was biotinylated so that four Cy5-molecules could be attached. Block III was labeled with 12 oligonucleotide probes of a total length of 232 bases. Each probe carried two FITC molecules. Block II was completely unlabeled. Due to the distance of $150 \mathrm{~kb}$ only, block I and block III were expected to co-localize in one PSF volume if the oligonucleotide probe combinations bound specifically. Figure 3 shows a typical example. Although background fluorescence was visible in all cell nuclei, typical, strong, point-like labeling sites were recorded at the same image position in both fluorescence detection channels.

Because the number of fluorochrome molecules in the two-color experiments were at the sensitivity limit of the microscope used, the low tem- (a)

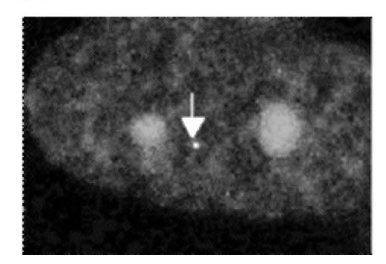

(b)

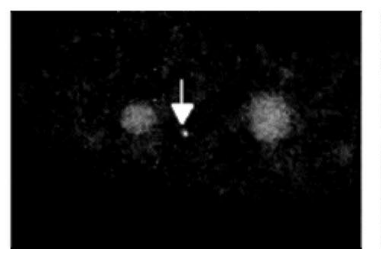

(c)

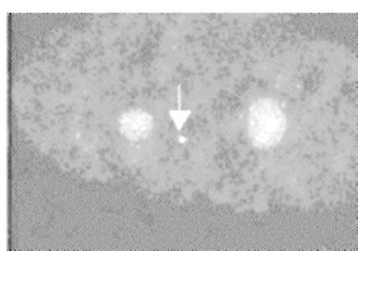

Figure 3. Fibroblast cell nucleus after specific labeling of the Abelson murine leukemia (ABL) region with two oligonucleotide probe combinations using the fast-fluorescence in situ hybridization (FISH) protocol. The cell nucleus was not counterstained so that the nuclear shape is only visible because of the labeling background. The two large objects are nucleoli that are accumulating oligonucleotide probes nonspecifically. (a) 2-D maximum intensity projection image [fluorescein isothiocyanate (FITC) channel]. The arrow indicates a signal obtained from 24 FITC molecules of 12 oligonucleotide probes of a total length of 232 bases (block III). (b) 2-D maximum intensity projection image (Cy5 channel). The arrow indicates a signal obtained from $32 \mathrm{Cy} 5$ molecules of 8 probes of a total length of 170 bases (block I). (c) Merged image of panels a and b. The arrow indicates the signal co-localization within the point spread function (PSF) volume. Note that the images are rough data with a $3 \times 3$ median filter and only global background subtraction.

(a)

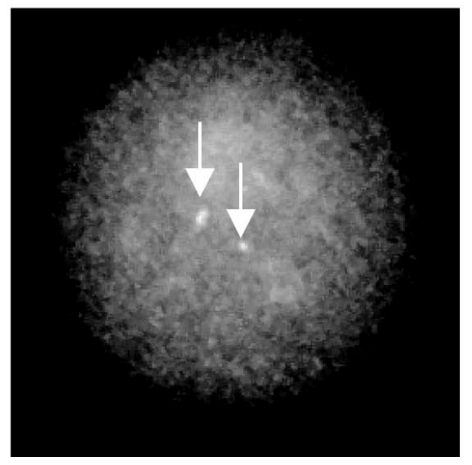

(b)

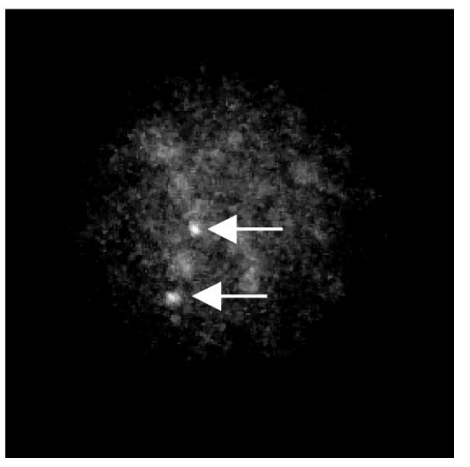

Figure 4. Example of lymphocyte cell nuclei with one-color fluorescein isothiocyanate (FITC) low temperature FISH labeling sites (homopyrimidine oligonucleotides of anti-parallel orientation to the purine target strand) of the Abelson murine leukemia (ABL) region. Arrows indicate 2-D maximum projection images (FITC channel only) after labeling at (a) $\mathrm{pH} 5.0$ and at (b) pH 5.5. Note that these images are rough data with a $3 \times 3$ median filter and only global background subtraction. 
perature FISH and the COMBO-FISH experiments were performed in one color with 32 homopyrimidine probes, which resulted in 64 FITC or Alexa 514 labeling molecules. These probes corresponded to the sequences shown in Table 3. Due to their orientation, only double-stranded binding was expected to occur for low temperature FISH, and only triple-stranded binding was expected to occur for COMBO-FISH.

The 32 homopyrimidine sequences of parallel orientation to their pyrimidine analogs were hybridized to the chromatin target in cell nuclei, which were not thermally denatured. The experiments were performed at four different $\mathrm{pH}$ values $(5.0,5.5,6.0$, and 6.5) without formamide application and at $37^{\circ} \mathrm{C}$ as the highest temperature applied to the target. Four different hybridization times were applied. For 25 and 50 $\mathrm{h}$, respectively, the results were similar;

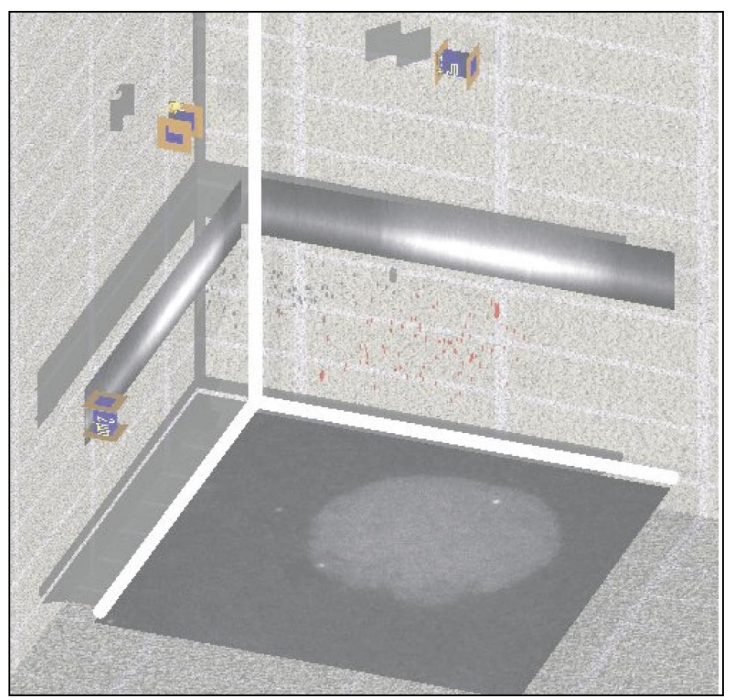

Figure 5. Example of a lymphocyte cell nucleus with one-color (Alexa 514) COMBO-FISH labeling sites (homopyrimdine oligonucleotides of parallel orientation to the purine target strand) of the Abelson murine leukemia (ABL) region. The center of the image shows a 3-D reconstruction of 25 confocal image sections. Because the cell nucleus was not counterstained, only signals from the probe material are visible. The small red dots are background signals (either unbound oligonucleotide probes or individually dispersed copies of the oligonucleotide probes bound anywhere in the genome but not in the ABL region). The larger red spots (arrows) refer to the optical fusion of the signals of all oligonucleotide probes that co-localize in the ABL region. The backsides of the image show the xz- and yz-projection of the cell nucleus. Due to the methanol/acetic acid fixation that was applied, the cell nucleus appears to be rather flat $(2-3 \mu \mathrm{m})$. At the bottom, the xy maximum intensity projection image can be seen, which indicates two intensive spots of the labeled regions (arrowheads). This projection image is compatible with the control images (Figures 3 and 4). Note that the images are rough data with a $3 \times 3$ median filter and only global background subtraction. it was therefore unnecessary to use the prolonged hybridization duration. The 00 and $200 \mathrm{~h}$ hybridization times renents were not further considered.

For each pH value, $20-40$ cell nuclei were recorded and evaluated. In general, a high fluorescence background ible. At pH 5.0 and 5.5, cell nuclei with the expected results.

COMBO-FISH with 32 homopyrimidine sequences of anti-parallel orientation to their pyrimidine analogs were hybridized to the chromatin target in cell nuclei that were not thermally denatured. The experiments were performed at $37^{\circ} \mathrm{C}$, as the highest temperature applied to the target. Only at a $\mathrm{pH}$ less than 6.0 were signals of intensities higher than background visible. For $24 \mathrm{~h}$ hybridization time, the results were similar to those obtained for low temperature FISH with homopyrimidine oligonucleotides of parallel orientation. Several hundred cell nuclei were evaluated by visual inspection of the image sections and interactive image analysis. On average, they showed a hybridization efficiency of approximately $17 \%$, [i.e., in about $17 \%$ of the cell nuclei, clearly identified point-like signals (2-4 spots) were found]. Figure 5 presents a typical example.

\section{DISCUSSION}

In principle, with the use of FISH $(1,2)$, every DNA sequence in the genome can be visualized with high specificity and sensitivity. However, all FISH protocols that are routinely used (3) require denaturation [usually done by heat treatment (5) in combination with chaotropic agents] of the dsDNA target to hybridize the single-stranded DNA probe by Watson-Crick bonding. Currently, these FISH protocols are incompatible with vital cell conditions and cannot be applied to in vivo investigations. In this report, we have introduced the concept of COMBO-FISH, which completely omits denaturation of the DNA target. Therefore, in principle, COMBO-FISH may be an approach that under vital cell conditions should allow for the labeling of a large variety of genomic regions in a cell nucleus, without the prior necessity of functionally modifying the genome, as is currently done [e.g., by using lac operator/repressor recognition $(8,9,33)]$.

A fundamental prerequisite for COMBO-FISH is the individual colocalization of several homopurine/homopyrimidine sequences at the given labeled site. In the human genome, the existence of such sequences was tested for about $1 \%$ of the entire sequence. Because the entries for this analysis were chosen by random access, the theoretical results for the part of the genome studied may be extended to the whole genome (E. Schmitt, M. Hausmann, manuscript in preparation). If, for simplicity, an average length of 15 nucleotides is assumed and the human genome with about $3 \times 10^{9} \mathrm{bp}$ (haploid set) contains $3 \times 10^{7}$ bp (1\%) in such triple-stranded forming helix structures, $3 \times 10^{7} / 15=2 \times 10^{6}$ segments for COMBO-FISH should exist. Therefore, $2^{15}\left(3 \times 10^{4}\right)$ variations in the nucleotide sequence of a homopurine/ homopyrimidine 15-mer are possible. Consequently, each 15 -mer should exist on average only in $2 \times 10^{6} / 3 \times 10^{4}$ $=67$ copies in the whole genome. If one assumes that not only 15 -mers are used for COMBO-FISH, then this copy number is much lower.

In these experiments of COMBOFISH, the technique has been developed for and applied to fixed material only. For instance, the RNase A and pepsin treatment are steps in the protocol that have to be avoided in experiments in vivo. However, the aim of this article was primarily to describe the basic principles of COMBO-FISH and to show experiments for the proof-of-principle 
of oligonucleotide combination and labeling without the use of the conventional FISH denaturation conditions. The two-color fast-FISH experiments and the pH-dependent, compatible labeling spots in the low temperature FISH experiments indicate specific probe binding, which was also found in the COMBO-FISH experiments.

Against a real triple helical probe binding in COMBO-FISH, it may be argued that methanol/acetic acid fixation or the applied $\mathrm{pH}$ could have sufficiently strong denaturing effects on the target DNA by itself. Consequently, the method described would fail under really nondenaturing vital conditions. Currently, it is difficult to exclude this possibility. However, most likely a mixture of double-stranded and singlestranded DNA already exists under native conditions (47). Furthermore, the homopyrimidine probes used in the COMBO-FISH experiments described here had an orientation that was antiparallel to the native pyrimidine strand, which should inhibit the formation of a double-stranded probe-target hybrid in the case of a denatured DNA target strand. However, this argument does not exclude the possibility of binding to another neighboring site with the appropriate orientation.

FISH efficiency has yet to be optimized experimentally. One may consider that the relatively low efficiency might be a result of point-like probe aggregates occurring in the cell nuclei by change. However, such aggregates should also be found in cell nuclei that do not show a cluster of the oligonucleotide probes used at a certain genome locus and that were treated according to the same specimen preparation and COMBO-FISH protocol. Experiments with the cell nuclei of a mouse cell line did not show signals of the typical size as reported earlier. The visual inspection of more than 100 cell nuclei only revealed aggregates of larger size that could not be interpreted as a COMBOFISH label (data not shown).

In the fast-FISH, low temperature FISH, and COMBO-FISH experiments, the oligonucleotide probes did not result in easily detectable fluorescence signals on metaphase spreads that would have unequivocally demonstrated the specificity and sensitivity of the label. The DNA compactness of the metaphase chromosomes used might have influenced the accessibility of the oligonucleotide probes. The electrostatic forces of the DNA backbone are repulsive on the probes. Due to the higher concentration of charged backbone phosphates, these forces might have been stronger in the metaphase chromosomes than in the interphase chromatin. To overcome this shortcoming, metaphase chromosomes might be treated differently or neutral peptide nucleic acid (PNA) oligonucleotide probes (48) might be used instead of negatively charged DNA probes. In spite of these remaining difficulties, the fact that by using a pool containing a considerable number of different oligonucleotide sequences, the labeling of interphase nuclei occurred as predicted by the theory and selection of the probe sequences due to bioinformatics data, strongly argues in favor of a very specific binding.

On the basis of the theoretical predictions and the outcome of the preliminary experiments reported here, COMBO-FISH appears to offer a challenging new potential for further developments using FISH under more vital cell conditions (i.e., under conditions that avoid the severe denaturation of both DNA and proteins inherent in conventional FISH protocols). In addition to the experimental procedures of microinjection of the oligonucleotide probes or other transport mechanisms such as membrane vesicles, the optimum probe concentration for the migration process into the vital cell nucleus and the fluorescence labeling strategy of the probes are still questions for further study. In principle, the feasibility of all these experimental delivery procedures has been shown $(49,50)$.

The identification of a fluorescence label as a specific COMBO-FISH site strongly depends on the signal-to-background ratio (45), which, in the case of 
COMBO-FISH, is given by the ratio of bound to unbound oligonucleotide probes. Because the amount of unbound probes is hardly to be influenced under vital cell conditions by washing processes, other approaches have to be considered to increase the signal-to-background ratio. One of these approaches may be the use of so-called smart-probes (46), which are oligonucleotide probes that quench the fluorescence emission of the dye as long as they are not specifically coupled to a complementary DNA sequence or that change their fluorescence lifetime upon complementary binding.

In addition to the many experimental questions being considered for further investigation, principle questions of COMBO-FISH in living cells still have to be answered. One of them is the in vivo accessibility of the homopurine target sequences for the oligonucleotide probes. If the formation of native triple helices were involved in the in vivo chromatin organization in the cell nucleus (51), it would then be possible, depending on the genetic activity, that probe-target triple strands would not bind to any given genome locus because of the spatial occupation of the target sequence. Furthermore, the binding sites might be tightly occupied by proteins. However, it is obvious that the differential accessibility of oligonucleotides to specific chromatin sites by itself would provide an effective tool to probe the functional nuclear organization on the nanostructure scale for specific sites (6). However, a satisfactory answer to such open questions requires systematic studies and future research.

Regardless of the questions concerning triple-stranded formation in the cell nuclei, a general FISH method allowing for the labeling of individual gene regions without specific denaturation steps (beyond that possibly induced by a conventional fixation) or the need for the suppression of repetitive sequences should already be very useful by its simplicity and sensitivity (about $1 \mathrm{~kb}$ or less of labeled sequences detected).

In conclusion, COMBO-FISH appears to be a feasible and gentle alternative to other DNA labeling procedures and might even be applicable under vital cell conditions. If so, it will offer new possibilities for the study of the functional dynamic architecture of the human genome and other species (6). Experimental tools to optimize the procedure are now at hand. Future research and developments should combine these tools to create, at a minimum, a unique labeling protocol.

COMBO-FISH has only been applied to the human genome. However, there is no obvious reason why the same principle could not be applied to any other species for which sequence data are available. The programs developed for oligonucleotide selection and combination can also be applied to databases of other sequenced species (e.g., Mus musculus). If the composition of the genome of mammals follows principal similarities to the human genome, then the COMBO-FISH approach has the advantage that, for any given locus of a sequenced species, a set of labeling probes can be designed that can be automatically synthesized without any complex probe generation by molecular biology methods. A preliminary check of the genome of $M$. musculus revealed for instance that the IgH locus on the mouse chromosome 12 (52) contains appropriate homopurine/ homopyrimidine sequences.

\section{ACKNOWLEDGMENTS}

The authors gratefully acknowledge the financial support of the German Federal Minister for Education and Research $(B M B F)$. This project was funded by BMBF grant no. $13 N 8350$ to M.H. and C.C. The authors also acknowledge the financial support of the BASF AG, Ludwigshafen, for preliminary experiments and the fruitful discussions with H. Eipel. M.H. was partly funded by a NCI/CCR Intramural Research Award (to S.J), Center for Cancer Research, National Institutes of Health, Bethesda, USA. The authors thank Dr. M. Durm, Dr. R. Heintzmann, Dr. J. Rauch, and Dr. R. Ventzki for their support. Special thanks to H. Dittmar for technical assistance. COMBOFISH is a patent application by C.C., T. Cremer, and M.H.

\section{REFERENCES}

1.Anguiano, A. 2000. Fluorescence in situ hybridization (FISH): overview and medical applications. J. Clin. Lig. Assay 23:33-42.
2.Van der Ploeg, M. 2000. Cytochemical nucleic acid research during the twentieth century Eur. J. Histochem. 44:7-42.

3.Clark, M. 1996. In Situ Hybridization. CRC Press, Boca Raton, FL.

4.Langer-Safer, P.R., M. Levine, and D.C. Ward. 1982. Immunological method for mapping genes on Drosophila polytene chromosome. Proc. Natl. Acad. Sci. USA 79: 4381-4385.

5.Rauch, J., D. Wolf, M. Hausmann, and C. Cremer. 2000. The influence of formamide on thermal denaturation profiles on DNA and metaphase chromosomes in suspension. Z Naturforsch. C55:737-746.

6.Cremer, T. and C. Cremer. 2001. Chromosome territories, nuclear architecture and gene regulation in mammalian cells. Nat. Rev. Genet. 2:292-301.

7.Zink, D. and T. Cremer. 1998. Chromosome dynamics in nuclei of living cells. Curr. Biol. 8:R321-R324.

8.Robinett, C.C., A. Straight, G. Li, C. Willhelm, G. Sudlow, A. Murray, and A.S. Belmont. 1996. In vivo localisation of DNA sequences and visualisation of large-scale chromatin organisation using lac operator/ repressor recognition. J. Cell Biol. 135:16851700.

9.Tsukamoto, T., N. Hashiguchi, S.M. Janicki, T. Tumbar, A.S. Belmont, and D.L. Spector. 2000. Visualization of gene activity in living cells. Nat. Cell Biol. 2:871-878.

10.Tumbar, T. and A.S. Belmont. 2001. Interphase movements of a DNA chromosome region modulated by VP16 transcriptional activator. Nat. Cell Biol. 3:134-139.

11.Celeda, D., K. Aldinger, F.-M. Haar, M. Hausmann, M. Durm, H. Ludwig, and C. Cremer. 1994. Rapid fluorescence in situ hybridization with repetitive DNA probes: quantification by digital image analysis. $\mathrm{Cy}$ tometry $17: 13-25$.

12.Durm, M., F.-M. Haar, M. Hausmann, H. Ludwig, and C. Cremer. 1996. Optimization of fast-fluorescence in situ hybridization with repetitive $\alpha$-satellite probes. Z. Naturforsch. 51C:253-261.

13.Haar, F.-M., M. Durm, K. Aldinger, D. Celeda, M. Hausmann, H. Ludwig, and C. Cremer. 1994. A rapid FISH technique for quantitative microscopy. BioTechniques 17: 346-353.

14.Haar, F.-M., M. Durm, M. Hausmann, H. Ludwig, and C. Cremer. 1996. Optimization of Fast-FISH for $\alpha$-satellite DNA probes. J. Biochem. Biophys. Methods 33:43-54.

15.Kraus, M., M. Hausmann, R. Hartig, M. Durm, F.-M. Haar, and C. Cremer. 1995. Non-enzymatic, low temperature in situ hybridization of metaphase chromosomes for magnetic labelling and sorting. Exp. Techn. Phys. 41:139-153.

16.Durm, M., F.-M. Haar, M. Hausmann, H. Ludwig, and C. Cremer. 1997. Non-enzymatic, low temperature fluorescence in situ hybridization of human chromosomes with a repetitive $\alpha$-satellite probe. Z. Naturforsch. $52 C: 82-88$

17.Winkler, R., B. Perner, A. Rapp, M. Durm, C. Cremer, K.O. Greulich, and M. Hausmann. 2003. Labelling quality and chromo- 
some morphology after low temperature FISH analysed by scanning far-field and scanning near-field optical microscopy. J. Microsc. 209:23-33.

18.Hausmann, M., B. Perner, A. Rapp, H. Scherthan, and K.O. Greulich. 2001. SNOM imaging of mitotic and meiotic chromosomes. Microsc. Anal. (Europ. Ed.) 7:13-15.

19.Ikemura, T., M. Ohno, T. Uemura, H. Sasaki, and T. Tenzen. 1998. Genome and subnuclear organization of non-B forming DNAs in mammalian chromosomes. Cytogenet. Cell Genet. 81:101-102.

20.Johnson, M.D. and J.R. Fresco. 1999. Thirdstrand in situ hybridization (TISH) to non-denatured metaphase spreads and interphase nuclei. Chromosoma 108:181-189.

21.Felsenfeld, G., D.R. Davies, and A. Rich. 1957. Formation of a three-stranded polynucleotide molecule. J. Am. Chem. Soc. 79: 2023-2024.

22.Felsenfeld, G. and A. Rich. 1957. Studies on the formation of two and three stranded polynucleotides. Biochim. Biophys. Acta 26: 457-468.

23.Felsenfeld, G. and H.T. Miles. 1967. The physical and chemical properties of nucleic acids. Ann. Rev. Biochem. 26:407-468.

24.Reither, S. and A. Jeltsch. 2002. Specificity of DNA triple helix formation analyzed by a FRET assay. BMC Biochem. 3:27-35.

25.Frank-Kamenetskii, M.D. and S.M. Mirkin. 1995. Triplex DNA structures. Annu. Rev. Biochem. 64:65-95.

26.Radhakrishnan, I. and D.J. Patel. 1994 DNA triplexes: solution structures, hydration sites, energetics, ions, and function. Biochemistry 33:11405-11416.

27.Sun, J.S., T. Garestier, and C. Helene. 1996. Oligonucleotide directed triple helix formation. Curr. Opin. Struct. Biol. 6:327-333.

28.Faria, M. and C. Giovannangeli. 2001. Triplex-forming molecules: from concepts to applications. J. Gene Med. 3:299-310.

29.Knauert, M.P. and P.M. Glazer. 2001 Triplex forming oligonucleotides: sequence specific tools for gene targeting. Hum. Mol. Genet. 10:2243-2251.

30.Praseuth, D., A.L. Guieysee, and C. Helene. 1999. Triple helix formation and the antigene strategy for sequence-specific control of gene expression. Biochim. Biophys. Acta 1489: 181-206.

31.Vasquez, K.M. and J.H. Wilson. 1998. Triplex-directed modification of genes and gene activity. Trends Biochem. Sci. 23:4-9.

32.Molenaar, C., S. Khazen, R. Dirks, T. Raap, and H. Tanke. 2000. Strategies und use of FISH applied to live cells. Cell. Mol. Biol. 46: Abstract 155

33.Cremer, C., M. Hausmann, and T. Cremer. 1997. Markierung von Nukleinsäuren mit speziellen Probengemischen (Labelling of nucleic acids by specific probe mixtures) Offenlegungsschrift DE 19806962 A1, Deutsches Patentamt München (Offenlegungstag 1.10.1998)

34.Edelmann, P. and C. Cremer. 2000. Improvement of confocal spectral precision distance microscopy (SPDM). Proc. SPIE 3921:313-320.

35.Konstatinides, K. and J. Rasure. 1994. The
Khoros software development environment for image and signal processing. IEEE Trans. Im. Proc. 3:243-252.

36.Burkholder, G.D., L.J.P. Latimer, and J.S. Lee. 1988. Immunofluorescent staining of mammalian nuclei and chromosomes with a monoclonal antibody to triplex DNA. Chromosoma 97:185-192.

37.Lee, J.S., G.D. Burkholder, L.J.P. Latimer, B.L. Haug, and R.P. Braun. 1987. A monoclonal antibody to triplex DNA binds to eucaryotic chromosomes. Nucleic Acid Res. 15:1047-1061.

38.Mergny, J.L., J.S. Sun, M. Rougee, T. Mont-Garestier, F. Barcelo, J. Chomilier, and C. Helene. 1991. Sequence specificity in triple-helix formation: experimental and theoretical studies of the effects of mismatches on triplex stability. Biochemistry 30:9791-9798.

39.Breslauer, K.J., R. Frank, H. Blocker, and L.A. Marky. 1986. Predicting DNA duplex stability from the base sequence. Proc. Natl Acad. Sci. USA 83:3746-3750.

40.Roberts, R.W. and D.M. Crothers. 1991. Specificity and stringency in DNA triplex formation. Proc. Natl. Acad. Sci. USA 88: 9397-9401.

41.Völker, J., D.P. Botes, G.G. Lindsey, and H.H. Klump. 1993. Energetics of a stable intramolecular DNA triple helix formation. J. Mol. Biol. 230:1278-1290.

42.Cheng, A.J. and M.W. Van Dyke. 1994. Oligodeoxyribonucleotide length and sequence effects on intermolecular purine-purine-pyrimidine triple helix formation. Nucleic Acids Res. 22:4742-4747.

43.Lee, J.S., D.A. Johnson, and A.R. Morgan. 1979. Complexes formed by (pyrimidine) ${ }_{\mathrm{n}} \bullet$ (purine) ${ }_{\mathrm{n}}$ DNAs on lowering the $\mathrm{pH}$ are threestranded. Nucleic Acid Res. 6:3073-3089.

44.Floris, R., B. Scaggiante, G. Manzin, F. Quadrifoglio, and L.E. Xodo. 1999. Effect on cations on purine-purine-pyrimidine triple helix formation in mixed valence salt solutions. Eur. J. Biochem. 260:801-809.

45.Bornfleth, H., K. Sätzler, R. Eils, and C. Cremer. 1998. High precision distance measurements and volume-conserving segmentation of objects near and below the resolution limit in three-dimensional confocal fluorescence microscopy. J. Microsc. 189:118-136.

46.Knemeyer, J.-P., N. Marmé, and M. Sauer. 2000. Probes for detection of specific DNA sequences at the single-molecule level. Anal. Chem. 72:3717-3724.

47.Dobrucki, J. and Z. Darzynkiewicz. 2001. Chromatin condensation and sensitivity of DNA in situ to denaturation during cell cycle and apoptosis-a confocal microscopy study. Micron 32:645-652.

48.Nielson, P.E. 1995. DNA analogues with nonphosphordiester backbones. Ann. Rev. Biophys. Biomol. Struct. 24:167-183.

49.Hartig, R., R.L. Shoeman, A. Janetzko, S. Grüb, and P. Traub. 1998. Active nuclear import of single-stranded oligonucleotides and their complexes with non-karyophilic macromolecules. Biol. Cell 90:407-426.

50.Hartig, R., R.L. Shoeman, A. Janetzko, G. Tolstonog, and P. Traub. 1998. DNA-mediated transport of the intermediate filament protein vimentin into the nucleus of cultured cells. J. Cell Sci. 111:3573-3584.

51.Vogt, P. 1990. Potential genetic functions of tandem repeated DNA sequence blocks in the human genome are based on a highly conserved "chromatin folding code". Hum. Genet. 84:301-306.

52.Kovalchuk, A.L., A. Esa, A.E. Coleman, S.S. Park, T. Ried, C. Cremer, and S. Janz. 2001. Translocation remodeling in the primary BALB/c plasmocytoma TEPC 3610 . Genes Chromosomes Cancer 30:282-291.

Received 28 January 2003; accepted 12 June 2003.

Address correspondence to:

Michael Hausmann

Pathologisches Institut

Albertstr. 19

D-79104 Freiburg, Germany

e-mail: mihaus@ukl.uni-freiburg.de

or

hausmann@kip.uni-heidelberg.de 